\title{
Stage IV Prostate Cancer AJCC v8
}

National Cancer Institute

\section{Source}

National Cancer Institute. Stage IV Prostate Cancer A/CC v8. NCI Thesaurus. Code C140173.

Stage IV includes: IVA: Any T, N1, M0, PSA: Any, Grade Group: Any; IVB: Any T, N0, M1, PSA: Any, Grade Group: Any. N0: Prostate cancer with no positive regional nodes. N1:

Prostate cancer with metastases in regional node(s). M0: Prostate cancer without evidence of distant metastasis. M1: Prostate cancer with distant metastasis. (AJCC 8th ed.) 